\title{
EFFECTS OF 6-HYDROXYDOPAMINE ON VISUAL DEPRIVATION IN THE KITTEN STRIATE CORTEX ${ }^{1}$
}

\author{
N. W. DAW, R. K. RADER, T. W. ROBERTSON, ${ }^{2}$ AND M. ARIEL ${ }^{3}$ \\ Department of Physiology and Biophysics, Washington University School of Medicine, St. Louis, Missouri 63110
}

Received August 30, 1982; Revised November 22, 1982; Accepted November 23, 1982

\begin{abstract}
We tested the effects of 6-hydroxydopamine (6-OHDA) on two forms of visual deprivationmonocular and directional deprivation. In normal kittens monocular deprivation leads to a change in the ocular dominance histogram recorded from the visual cortex, and directional deprivation leads to a change in the percentage of directionally sensitive cells responding to the appropriate direction of movement. 6-OHDA was infused into the occipital cortex prior to the peak of the critical period for the effects of visual deprivation. In agreement with the results of Kasamatsu et al. (Kasamatsu, T., and J. D. Pettigrew (1979) J. Comp. Neurol. 185: 139-162; Kasamatsu, T., J. D. Pettigrew, and M. Ary (1979) J. Comp. Neurol. 185: 163-182), suture of one eye (monocular deprivation) after the 6-OHDA treatment did not lead to a shift in ocular dominance in the area of striate cortex infused. Moreover, rearing kittens in an environment continually moving past them in one direction (directional deprivation) did not lead to a change in the percentage of cells preferring movement in that direction. In both rearing procedures the 6-OHDA did not make the cells in the cortex nonspecific, compared to cells recorded from the cortex of animals reared similarly but without infusion of 6-OHDA.

Monocular and directional deprivation are forms of visual deprivation with different critical periods, probably involving different synapses. Therefore, the effect of 6-OHDA on visual deprivation is a general one, involving more than one kind of visual deprivation. In both cases 6-OHDA abolishes the plasticity of the visual cortex.
\end{abstract}

Recent experiments by Kasamatsu and Pettigrew $(1976,1979)$ have shown that 6-hydroxydopamine (6OHDA), when administered to kittens during the critical period for plasticity in the visual cortex, prevents the effects of visual deprivation. The classic example of visual deprivation is monocular deprivation. The eyelids of one eye of a kitten are sutured shut. The retina of that eye receives light, but most form and much movement cannot be seen. When the eyelids are sutured during the critical period ( 2 weeks to several months of age, with greatest sensitivity at 4 to 5 weeks), the cells in the visual cortex become dominated by the open eye and very few cells can be driven by the closed eye. This is referred to as a

\footnotetext{
${ }^{1}$ The research was supported by Program Project Grant NS 15070 and National Institutes of Health Research Grant EY 00053. M. A. was supported by Training Grant EY 07057. We thank Dr. T. Kasamatsu for advice on methods, D. Schreyer for helping with some of the early experiments, and $\mathrm{T}$. Videen with a few of the later ones. We also thank J. Cohen for the histology and S. Eads for typing the manuscript.

${ }^{2}$ Present address: School of Optometry, University of Missouri, 8001 Natural Bridge, St. Louis, MO 63121.

${ }^{3}$ Present address: Biology Department, Harvard University, $16 \mathrm{Di}$ vinity Avenue, Cambridge, MA 02138.
}

shift in ocular dominance (Wiesel and Hubel, 1963; Hubel and Wiesel, 1970; for recent summaries see Movshon and van Sluyters, 1981; Sherman and Spear, 1982).

If the eye is sutured a few days after 6-OHDA is infused into the ventricles, the shift in ocular dominance does not occur (Kasamatsu and Pettigrew, 1976, 1979). Similarly, if 6-OHDA is infused locally into the cortex, this also prevents the shift in ocular dominance (Kasamatsu et al., 1979). The prime action of 6-OHDA is to act as a neurotoxin on catecholamine neurons (Bloom et al., 1969; Uretsky and Iversen, 1970; Ungerstedt, 1971; for review see Jonsson, 1980). In agreement with this, an ocular dominance shift to the open eye does occur if norepinephrine (NE) is infused into cortex previously depleted by 6-OHDA (Pettigrew and Kasamatsu, 1978; Kasamatsu et al., 1979). The ocular dominance shift can be reversed within the critical period by reopening the sutured eye. This shift can also be suppressed by 6OHDA and accelerated by NE (Kasamatsu et al., 1981b).

Another type of visual deprivation is to rear kittens in an environment that continually moves in one direction. The majority of directionally sensitive cells recorded in the visual cortex of these kittens prefer movement in the direction that the environment moved during rearing: a 
minority prefer movement in the opposite direction (Cynader et al., 1975; Tretter et al., 1975; Daw and Wyatt, 1976). This form of visual deprivation differs from monocular deprivation in at least two respects. First, the critical period ends somewhat earlier (Daw and Wyatt, 1976; Berman and Daw, 1977; Daw et al., 1978). Second, the synapses involved are almost certainly different: binocularity in the visual cortex involves the convergence of inputs from different layers of the lateral geniculate with excitatory connections, whereas direction selectivity involves intracortical lateral inhibitory GABA connections which can be abolished briefly by iontophoresis of the GABA antagonist bicuculline (Sillito, 1977). Because NEcontaining terminals are located throughout the kitten occipital cortex (Itakura et al., 1981), one might speculate that the effect of 6-OHDA is general and should apply to other types of visual deprivation. Directional deprivation is, therefore, a particularly good test of the generality of the effect of 6-OHDA on plasticity in the kitten visual cortex.

\section{Materials and Methods}

The kittens were kept with their mother until weaning. Shortly after eye opening they were put in the dark to avoid exposure to unwanted stimuli. Feeding and cleaning were carried out in the dark.

Administration of 6-OHDA. At approximately $3^{1 / 2}$ weeks of age an infusion cannula was implanted in the kitten's occipital cortex under halothane anesthesia. A small hole was made in the bone over the left occipital cortex at approximately P5, L1-2 and a short beveled 26gauge hypodermic needle was inserted (Kasamatsu et al., 1979). The bevel faced anteriorly, and the tip was placed 1 to $2 \mathrm{~mm}$ below the surface of the cortex. The needle shank was cemented to the skull with acrylic dental cement, and its other end was attached to a short length of vinyl tubing which led to an osmotic minipump (Alza Corp., Model 2001). The minipump contained $1 \mathrm{mg} / \mathrm{ml}$ of 6-OHDA (Sigma) dissolved in sterile normal saline containing $0.4 \%$ ascorbate. It was placed subcutaneously at the neck and delivered its contents $(170 \mu \mathrm{l})$ at a rate of $1 \mu \mathrm{l} / \mathrm{hr}$ over a period of about 1 week, after which infusion was terminated. This procedure has been shown to produce a chemical lesion of catecholamine-containing neurons in the cortex for a radius of at least $5 \mathrm{~mm}$ around the tip of the needle (Kasamatsu et al., 1979, 1981a). Some kittens had a pump implanted containing only ascorbate in saline for control purposes.

Visual deprivation. We allowed about 2 days, with the kittens in the dark, for the 6-OHDA to be taken up and affect catecholamine neurons, then we commenced the visual deprivation procedures. For monocular deprivation the eyelids of one eye were sutured shut under halothane anesthesia (Wiesel and Hubel, 1963; Berman and Daw, 1977). The kittens were then brought into the light for about $7 \mathrm{hr} /$ day over the next week, for a total exposure of approximately $50 \mathrm{hr}$.

For directional deprivation, each kitten was placed inside a drum with vertical stripes on the inside wall (Daw and Wyatt, 1976; Berman and Daw, 1977). The drum rotated around the kitten at approximately $30^{\circ} \%$ sec. A transparent cylinder inside the drum kept the kitten at least $12 \mathrm{~cm}$ away from the wall of the drum. A black plastic collar prevented the kitten from seeing its own limbs, and black plastic discs prevented it from seeing out of the drum upward or downward. The kitten was exposed to stripes moving only in one direction for a total of approximately $50 \mathrm{hr}$ over 7 to 10 days and otherwise kept in the dark.

In order to achieve symmetry in the results, half the animals were left deprived and half right deprived. That is, half the monocularly deprived kittens had the left eye sutured and half had the right eye sutured. For the directionally deprived kittens, half were exposed to a drum moving to the left and half to a drum moving to the right.

Recording procedures. Kittens were recorded from as soon as possible after exposure to the appropriate stimulus (see Tables II and III). Recording procedures were conventional and have been described (Daw and Wyatt, 1976; Berman and Daw, 1977; Daw and Ariel, 1980). Each unit was characterized according to its type (simple or complex), direction selectivity, ocular dominance, orientation selectivity, velocity specificity, length and width specificity, spontaneous activity, and position in the field of view. For monocularly deprived animals, particular attention was paid to the ocular dominance, and each cell was placed into one of seven ocular dominance groups, as defined by Hubel and Wiesel (1959). For directionally deprived animals, particular attention was paid to the direction sensitivity. Cells with direction sensitivity were put into one of two categories-unidirectional or bidirectional. Some cells were obviously unidirectional, that is, they responded to movement in one direction and gave little or no response to movement in the opposite direction. Some cells were obviously bidirectional, that is, they responded to movement almost equally well in two directions opposite to each other and gave little or no response to movement in directions perpendicular to this axis. Where the distinction between unidirectional and bidirectional was ambiguous, a poststimulus time histogram was compiled for a stimulus of the preferred length, width, and velocity moving along the preferred axis (Daw and Ariel, 1980). The number of spikes fired for movement in the preferred direction was compared to the number of spikes fired for movement in the direction opposite to this, and a criterion of 2:1 was adopted to distinguish unidirectional cells from bidirectional cells. If this test was ambiguous, or if this test classified the cell as unidirectional at some velocities and bidirectional at others, the cell was counted as half unidirectional and half bidirectional.

Histological procedures. Each kitten was perfused with buffered formalin at the end of the recordings and its visual cortex sectioned and stained with cresyl violet for Nissl substance. The electrode tracks were reconstructed from lesions $(4 \mu \mathrm{A}$ for $10 \mathrm{sec})$ that were made periodically during the recordings. Sections were cut in the frontal plane to facilitate this reconstruction. The position of the tip of the needle was usually obvious, and the sections were examined for evidence of damage around this area. The distance of each electrode track from the needle was calculated. Penetrations which passed through damaged areas and penetrations more than $5 \mathrm{~mm}$ from the tip of the needle were excluded from the results. The position of each cell in relation to the 
layers of the cortex was also estimated, using the layering system of Kelly and van Essen (1974).

Calculation of weighted ocular dominance. In order to evaluate statistically the data collected from monocularly deprived animals, we calculated a weighted ocular dominance shift (Kasamatsu et al., 1981b) for each animal and for the total sample of cells recorded in each group. The fraction of dominance by the open eye was calculated as

$$
\frac{A+5 / 6 B+4 / 6 C+3 / 6 D+2 / 6 E+1 / 6 F}{A+B+C+D+E+F+G}
$$

where $A$ represents the number of cells in group $\mathrm{A}, B$ the number in group B, etc. (see legend to Fig. 1).

\section{Results}

\section{Effect of 6-OHDA on specificity of cells in the visual cortex}

Does 6-OHDA affect the specificity of cells in the cortex, suggesting that it produces a general disruption of cortical activity? To answer this question, we divided our kittens into four groups: (1) those treated with 6OHDA and given eye suture (monocular deprivation); (2) those given eye suture but not treated with 6-OHDA; (3) those treated with 6-OHDA and reared with stripes continually moving around them (directional deprivation); and (4) those reared with stripes continually moving around them but not treated with 6-OHDA. Recordings from kittens in group 1 were compared with those in group 2, and group 3 was compared with group 4 .

Each cell was classified as being unidirectional, bidirectional, omnidirectional, or hard to drive (see "Materials and Methods;" also Berman and Daw, 1977; Daw and Ariel, 1980). Cells with directional selectivity (unidirectional or bidirectional) are usually considered as having specific receptive field properties, and cells that respond to movement in all directions (omnidirectional) and cells that are hard to drive are not very common in normal animals and are usually considered to be nonspecific (cells identified as lateral geniculate afferents by their rate of firing or spike shape are excluded from the analysis). Table I shows the number of cells of each type recorded in each group of animals, together with the number of kittens in each group. The percentage of cells of each type is given in parentheses. A $\chi^{2}$ test comparing the distribution of cells in group 1 with those in group 2 shows that there is no significant difference $\left(n=3, \chi^{2}=\right.$ $4.85 ; p \approx 0.19$ ); a $\chi^{2}$ test comparing the distribution of cells in group 3 with those in group 4 shows that there is a difference which is statistically significant $\left(n=3 ; \chi^{2}=\right.$ $8.2 ; p \approx 0.04$ ); however, because removal of one animal (6A) from the results makes the difference not statistically significant $\left(\chi^{2}=3.45 ; p \approx 0.34\right)$, it is probably not biologically or experimentally significant. The percentage of cells in the omnidirectional category is high in all four groups, but this can be attributed to the rearing procedures, rather than to the effects of 6-OHDA (see "Discussion"). Although in the monocularly deprived groups, there were more omnidirectional cells when 6OHDA was used than when it was not, in the directionally deprived groups the reverse was true. Therefore, it seems clear that administration of 6-OHDA did not result in a general reduction in specificity of the cortex.

Monocularly deprived animals. We next assessed the effect of local perfusion of 6-OHDA on ocular dominance shifts in monocularly deprived animals in a manner similar to that of Kasamatsu et al. $(1979,1981)$ (some minor differences in procedure are noted in the "Discussion"). This was necessary to see if these rather difficult procedures would work in our laboratory, as well as to provide an independent confirmation of their results.

Seven kittens from four litters were used (number refers to litter number and letter to kitten within a litter). A summary of the age at pump insertion, the eye sutured, the period and duration of exposure to light, the age at recording, the cortex recorded, and treatment is given in Table II. Two kittens (19A and 19D) had only one eye exposed for $47 \mathrm{hr}$ at the peak of the critical period. Their

TABLE I

Type and number of cells studied

\begin{tabular}{lccccc}
\hline \multirow{2}{*}{ Type of Cell } & \multicolumn{2}{c}{ Monochlar Deprivation } & \multicolumn{2}{c}{ Directional Deprivation } \\
\cline { 2 - 3 } & $\begin{array}{c}\text { 6-OHDA } \\
\text { (Group 1) }\end{array}$ & $\begin{array}{c}\text { Control } \\
\text { (Group 2) }\end{array}$ & $\begin{array}{c}\text { 6-OHDA } \\
\text { (Group 3) }\end{array}$ & $\begin{array}{c}\text { Control } \\
\text { (Group 4) }\end{array}$ \\
\hline $\begin{array}{l}\text { no. of cells } \\
\text { Unidirectional }\end{array}$ & $35(34 \%)$ & $43^{1 / 2}(48 \%)$ & & $113^{1 / 2}(52 \%)$ & $181^{1 / 2}(46 \%)$ \\
Bidirectional & $42(40 \%)$ & $31^{1 / 2}(35 \%)$ & $65^{1 / 2}(30 \%)$ & $106^{1 / 2}(27 \%)$ \\
Omnidirectional & $24(23 \%)$ & $13(14 \%)$ & $28(13 \%)$ & $88(22 \%)$ \\
Hard to drive & $3(3 \%)$ & $3(3 \%)$ & $9(4 \%)$ & $16(4 \%)$
\end{tabular}

$\begin{array}{lrrrr}\text { Total } & 104 & 91 & 216 & 392 \\ \text { No. of kittens } & 3 & 4 & 6 & 10\end{array}$

TABLE II

Treatment of monocularly deprived kittens

\begin{tabular}{|c|c|c|c|c|c|c|c|c|c|}
\hline \multirow{2}{*}{ Animal } & \multirow{2}{*}{$\begin{array}{l}\text { Age at } \\
\text { Pump } \\
\text { Insertion }\end{array}$} & \multirow{2}{*}{$\begin{array}{c}\text { Eye } \\
\text { Suture }\end{array}$} & \multicolumn{2}{|c|}{ Exposure } & \multirow{2}{*}{$\begin{array}{c}\text { Age at } \\
\text { Recording }\end{array}$} & \multirow{2}{*}{$\begin{array}{c}\text { Cortex } \\
\text { Recorded }\end{array}$} & \multirow{2}{*}{$\begin{array}{l}\text { No. of Cells } \\
\text { Recorded }\end{array}$} & \multirow{2}{*}{$\begin{array}{l}\text { Weighted } \\
\text { Ocular } \\
\text { Dominance } \\
\text { Shift }\end{array}$} & \multirow{2}{*}{ Treatment } \\
\hline & & & Period & Duration & & & & & \\
\hline & weeks & & weeks & $h r$ & weeks & & & & \multirow{3}{*}{$\begin{array}{l}\text { Cortex not in- } \\
\text { fused }\end{array}$} \\
\hline $19 \mathrm{~A}$ & & Left & $3.8-5.3$ & 47 & 7 & Right & 17 & 0.62 & \\
\hline $19 \mathrm{D}$ & & Right & $3.8-5.3$ & 47 & 6 & Right & 30 & 0.77 & \\
\hline $12 \mathrm{D}$ & 4.7 & Right & $5.7-6.7$ & 62 & 14 & Left & 24 & 0.68 & \multirow{2}{*}{$\begin{array}{l}\text { Ascorbate in- } \\
\text { fusion }\end{array}$} \\
\hline $12 \mathrm{E}$ & 5.8 & Left & $6.3-7.2$ & 53 & 10 & Left & 15 & 0.80 & \\
\hline $10 \mathrm{C}$ & 3.6 & Right & $4.7-6.3$ & 55 & 8 & Left & 46 & 0.52 & \multirow{3}{*}{$\begin{array}{l}\text { 6-OHDA infu- } \\
\text { sion }\end{array}$} \\
\hline $12 \mathrm{~A}$ & 4.7 & Left & $5.7-6.7$ & 62 & 10 & Left & 20 & $0.71\}$ & \\
\hline $23 \mathrm{~B}$ & 3.6 & Right & $3.7-4.7$ & 50 & 6 & Left & 27 & $0.43 J$ & \\
\hline
\end{tabular}


right cortex was not infused and, therefore, served as a control. The ocular dominance histogram showed a paucity of binocularly driven cells and a substantial tendency for cells to be dominated by the open eye (Fig. 1A). Two kittens (12D and 12E) had one eye exposed for approximately the same duration, with a cannula in the visual cortex, connected to a minipump containing only $0.4 \%$ ascorbate in saline. The ocular dominance histogram for these two kittens was very similar to that for the first two (Fig. 1B). In both cases the ocular dominance shift was incomplete, but this can be attributed to the comparatively short period of monocular deprivation.

Figure $1 C$ shows the results for three monocularly reared kittens (10C, 12A, 23B) with 6-OHDA in the minipump. The ocular dominance histogram for these animals was much flatter, with a much higher percentage of cells dominated by the closed eye $(47 \%$ compared to $22 \%$ in the control groups, excluding group 4 cells in both cases). A weighted ocular dominance shift (see "Materials and Methods") was calculated for each animal (see Table II) and for the four control animals as a group (shift 0.72 , based on 86 cells) and for the three 6-OHDA animals as a group (shift 0.53 , based on 93 cells). These two proportions are significantly different from each other $(p \approx 0.01)$. These results, therefore, confirm the finding that infusion of 6-OHDA reduces ocular dominance shifts in monocularly reared kittens.

However, the properties of cells dominated by the open eye were not the same as the properties of those dominated by the closed eye (see Fig. 1). Of 44 cells dominated by the open eye, 41 had specific receptive field properties (unidirectional or bidirectional) and three had nonspecific receptive field properties (omnidirectional). Of 39 cells dominated by the closed eye, 21 had specific receptive field properties and 18 were nonspecific. These are significantly different proportions $\left(n=1 ; \chi^{2}=16.9 ; p<\right.$ 0.001 ). We conclude that the reduction in specificity that occurs for cells driven by a closed eye, as compared to cells driven by an open eye, is not prevented by 6-OHDA.

Directionally deprived animals. Sixteen kittens from seven litters were reared with exposure to a drum contin-

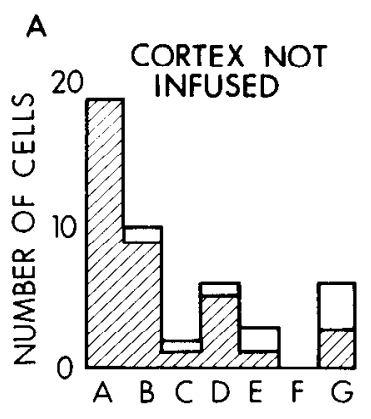

B

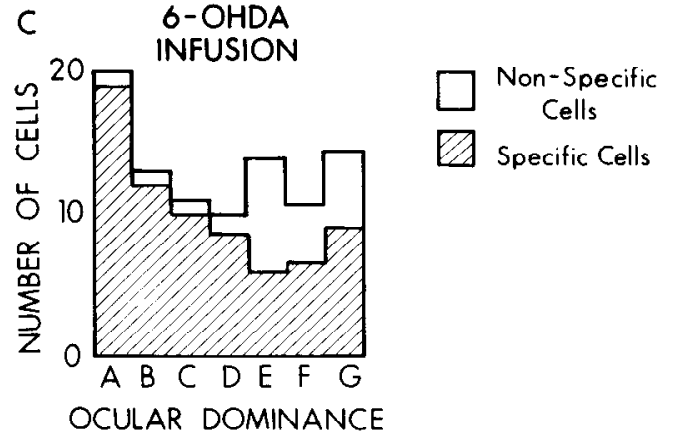

Figure 1. Ocular dominance histograms of monocularly deprived animals. Two control groups $(A$ and $B)$ are compared with a group with 6-OHDA infused into the cortex $(C)$. Because it was sometimes the contralateral eye and sometimes the ipsilateral eye that was sutured, the individual ocular dominance histograms have been combined, with group A representing cells driven only by the open eye, group $\mathrm{G}$ representing cells driven only by the sutured eye, group $\mathrm{D}$ representing cells driven equally by both eyes, and groups $\mathrm{B}, \mathrm{C}, \mathrm{E}$, and $\mathrm{F}$ representing the Hubel and Wiesel groups $2,3,5$, and 6 , or $6,5,3$, and 2, as appropriate. Hatched areas represent cells with specific receptive field properties (unidirectional or bidirectional), and open areas represent cells with nonspecific receptive field properties (omnidirectional).

ually moving in one direction (see Table III for details of treatment). Approximately 50 cells were sampled from each animal. However, a typical penetration yielded a variety of cell types of which many could not be used for

TABLE III

Treatment of directionally deprived kittens

\begin{tabular}{|c|c|c|c|c|c|c|c|}
\hline \multirow{2}{*}{ Animal } & \multirow{2}{*}{$\begin{array}{c}\text { Age at } \\
\text { Pump } \\
\text { Insertion }\end{array}$} & \multirow{2}{*}{$\begin{array}{l}\text { Direction } \\
\text { of Drum } \\
\text { Rotation }\end{array}$} & \multicolumn{2}{|c|}{ Exposure } & \multirow{2}{*}{$\begin{array}{c}\text { Age at } \\
\text { Recording }\end{array}$} & \multirow{2}{*}{$\begin{array}{c}\text { Cortex } \\
\text { Recorded }\end{array}$} & \multirow{2}{*}{ Treatment } \\
\hline & & & Period & Duration & & & \\
\hline & weeks & & weeks & $h r$ & weeks & & \\
\hline $4 \mathrm{D}$ & & Left & $3.4-4.3$ & 40 & 11 & Left & \multirow{6}{*}{ Cortex not infused } \\
\hline $4 \mathrm{E}$ & & Right & $3.4-4.3$ & 40 & 6 & Left & \\
\hline $5 \mathrm{D}$ & & Left & $3.9-4.9$ & 45 & 13 & Left & \\
\hline $6 \mathrm{~F}$ & & Right & $3.8-5.1$ & 44 & 15 & Left & \\
\hline $5 B$ & & Left & $3.9-4.8$ & 45 & 5 & Right & \\
\hline $18 \mathrm{~B}$ & & Right & $4.0-5.9$ & 49 & 7 & Right & \\
\hline $6 \mathrm{~A}$ & 3.7 & Right & $4.0-5.2$ & 44 & 16 & Left & \multirow[t]{2}{*}{ Saline infusion } \\
\hline $15 \mathrm{C}$ & 3.7 & Left & $4.2-5.7$ & 45 & 9 & Left & \\
\hline $17 \mathrm{C}$ & 3.6 & Right & $3.8-5.2$ & 43 & 7 & Left & \multirow[t]{2}{*}{ Ascorbate infusion } \\
\hline $17 \mathrm{D}$ & 3.7 & Left & $4.1-5.9$ & 45 & 10 & Left & \\
\hline $15 \mathrm{~A}$ & 3.6 & Left & $4.2-5.7$ & 47 & 7 & Left & \multirow{6}{*}{ 6-OHDA infusion } \\
\hline $15 \mathrm{~B}$ & 3.7 & Right & $4.2-5.7$ & 45 & 8 & Left & \\
\hline $17 \mathrm{~A}$ & 3.6 & Right & $3.9-5.2$ & 43 & 8 & Left & \\
\hline $18 \mathrm{~A}$ & 3.9 & Left & $4.0-5.9$ & 45 & 7 & Left & \\
\hline $18 B$ & 3.6 & Right & $4.0-5.9$ & 49 & 7 & Left & \\
\hline $19 \mathrm{C}$ & 3.6 & Left & $3.8-5.2$ & 49 & 7 & Left & \\
\hline
\end{tabular}


calculations of the effect of directional deprivation (Fig. 2). Cells not included in these results include bidirectional cells, cells without direction specificity, cells preferring up and down movement within $30^{\circ}$ of the vertical, and cells whose classification was doubtful. Consequently the cell sample remaining (20\% to $40 \%$ ) was pooled for each animal and a single fraction was calculated consisting of

no. of cells preferring movement in direction of drum

no. of cells preferring movement in drum direction

+ no. preferring opposite direction

For the purposes of calculating this fraction, cells with preferred directions on the boundary line $\left(30^{\circ}\right.$ away from the vertical) were counted as having a preferred direction half vertical and half left or right. The number of cells used to calculate this fraction for each animal is given in Table IV.

Six kittens were reared as a first set of controls. Four of them were not perfused with 6-OHDA, and two received it in the opposite cortex. The fractions calculated for these animals varied from 0.64 to 0.80 , with a fraction of 0.68 for the whole sample (Table IV). Thus, as a result of the rearing procedure, there were about twice as many cells preferring movement in the direction of the drum as cells preferring movement in the opposite direction, or a bias of approximately $2: 1$.

Four kittens were reared with a cannula implanted in the cortex containing control solutions in the attached minipump. In three cases (Table III) the control solution was $0.4 \%$ ascorbate in saline, and in one case it was saline. The fractions calculated for these animals varied from 0.60 to 0.69 with a fraction of 0.64 for the whole sample (Table IV). Thus, the infusion of the vehicle solution without 6-OHDA did not make a significant change in the bias of approximately $2: 1$ produced by the rearing procedure $\left(n=1 ; \chi^{2}=0.25 ; p \approx 0.6\right)$.

Six kittens were reared with infusion of 6-OHDA from a minipump into the cortex (Table III). The fractions for these animals ranged from 0.33 to 0.57 , with a fraction of 0.43 for the whole sample (Table IV). This directional bias is not significantly different from that expected and observed in normal animals, which is $0.5\left(n=1 ; \chi^{2}=\right.$ $0.93 ; p \approx 0.32$ ). However, it is significantly different from the sample of 10 directionally deprived control kittens $\left(n=1 ; \chi^{2}=10.8 ; p \approx 0.001\right)$. Infusion of 6 -OHDA did not make a noticeable difference to the ocular dominance histogram, the percentages of unidirectional, bidirectional, and omnidirectional cells (Table I), or the percentages of simple versus complex cells. Thus we conclude that infusion of 6-OHDA led to the disappearance of the direction selectivity bias which is usually seen in directionally deprived animals, without changing other properties of the cells recorded.

Histology. We reconstructed the entire area of the electrode penetrations and the cannula in serial sections. Figure 3 shows sections through the damage created by the cannula and 6-OHDA in two animals and sections containing lesions from the electrode tracks in the same animals. In some cases the damage from the cannula was slight, as in Figure $3 A$. In some cases the damage was extensive, as in Figure $3 C$, particularly when the tip of the cannula reached into white matter. However, the tissue in the region of the electrode tracks appeared normal (Fig. 3, $B$ and $D$ ). Where there was damage to white matter, it was posterior to the electrode tracks. If the electrode track passed through a damaged arca, the results from that penetration were excluded.

\section{Discussion}

The first result in this paper confirms the work of Kasamatsu et al. (1979) showing that continuous infusion of 6-OHDA into the visual cortex reduces the shift in

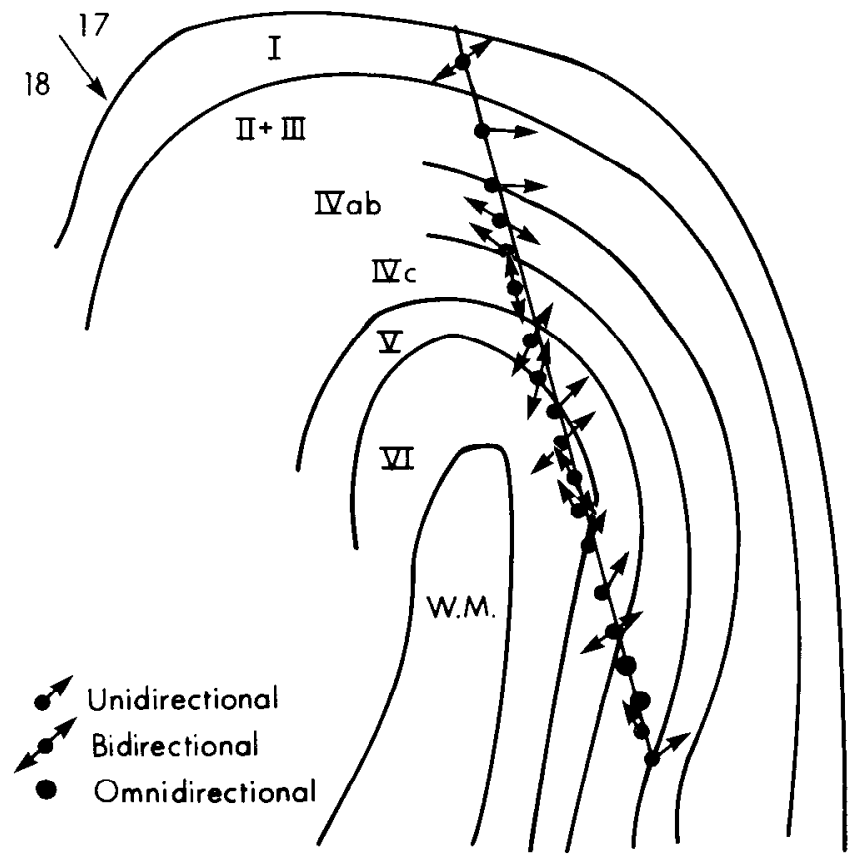

Figure 2. Reconstruction from frontal section of typical penetration into area 17 of left cortex. Dots mark position of cells recorded, and direction of arrows represents preferred direction of movement. Roman numerals represent layers of cortex; W.M., white matter. Position of boundary between Brodmann's areas 17 and 18 is also marked. This penetration was one of five from kitten 17A. Four unidirectional cells preferred movement right, and one preferred movement left.

TABLE IV

$\left.\begin{array}{cccc}\multicolumn{4}{c}{\text { Directional bias produced by various treatments }} \\ \hline \text { Animal } & \text { Fraction } & \text { No. of Cells } & \text { Treatment } \\ \hline 4 \mathrm{D} & 0.70 & 13^{1 / \underline{1}} & \\ 4 \mathrm{E} & 0.67 & 18^{1 / 2} \\ 5 \mathrm{D} & 0.64 & 5 & \text { No infusion } \\ 6 \mathrm{~F} & 0.80 & 5 & \\ 5 \mathrm{~B} & 0.64 & 12^{1 / 2} \\ 18 \mathrm{~B} & 0.71 & 12^{1 / 2}\end{array}\right\} \quad \begin{aligned} & \text { Cortex not in- } \\ & \text { fused }\end{aligned}$

Fraction for whole sample $=0.68$

$\left.\begin{array}{llcl}6 \mathrm{~A} & 0.69 & 8 & \\ 15 \mathrm{C} & 0.60 & 20 \\ 17 \mathrm{C} & 0.68 & 9^{1 / 2} \\ 17 \mathrm{D} & 0.64 & 11\end{array}\right\} \quad \begin{aligned} & \text { Saline } \\ & \text { Ascorbate in- } \\ & \text { fusion }\end{aligned}$

Fraction for whole sample $=0.64$

\begin{tabular}{|c|c|c|c|}
\hline $15 \mathrm{~A}$ & $0.4 \mathrm{I}$ & 17 & \\
\hline $15 \mathrm{~B}$ & 0.42 & 19 & \\
\hline $17 \mathrm{~A}$ & 0.57 & $17^{1 / 2}$ & 6-OHDA infu- \\
\hline $18 \mathrm{~A}$ & 0.35 & $8^{1 / 2}$ & sion \\
\hline $18 \mathrm{~B}$ & 0.35 & $81 / 2$ & \\
\hline $19 \mathrm{C}$ & 0.33 & 9 & \\
\hline
\end{tabular}

Fraction for whole sample $=0.43$ 

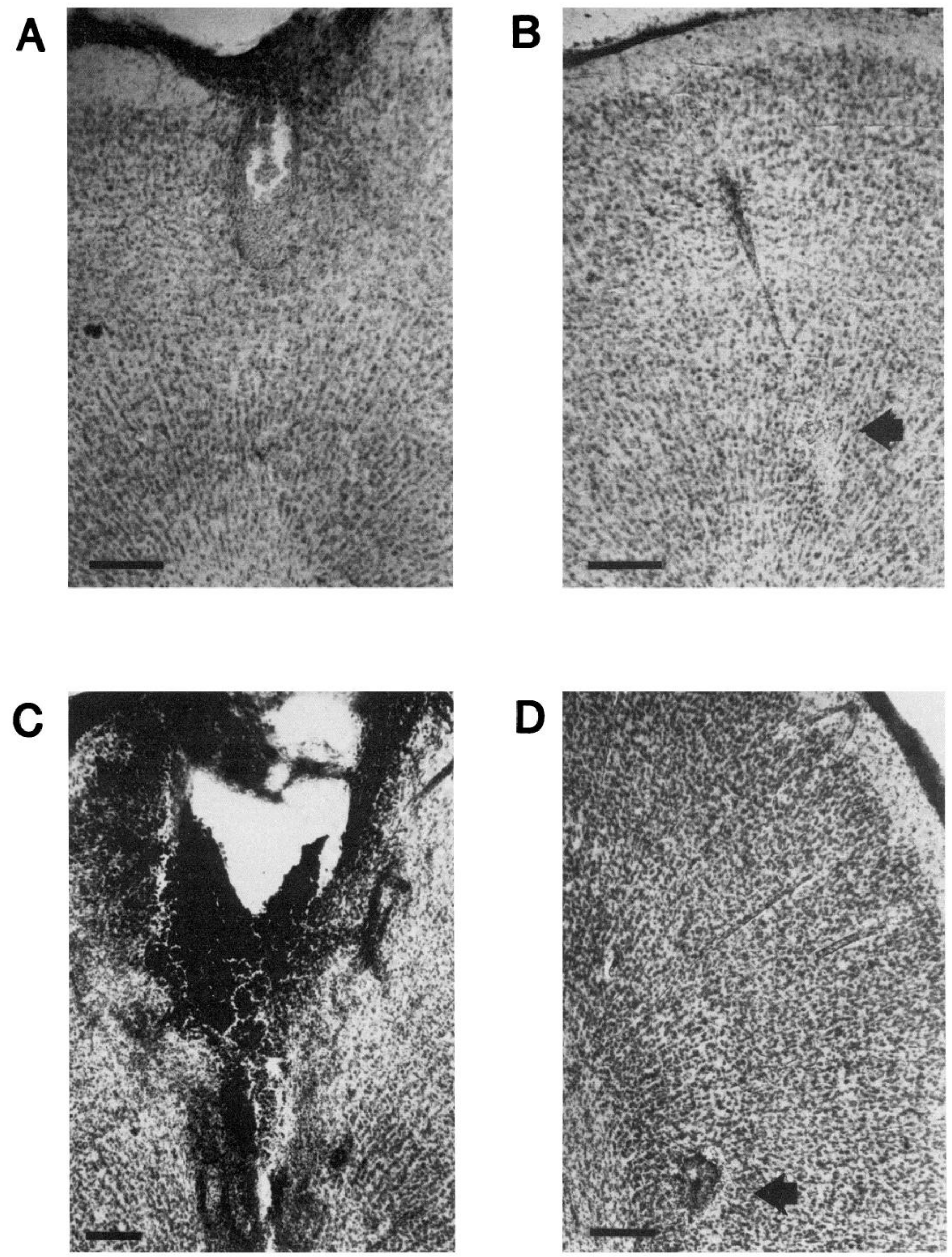

Figure 3. Frontal sections showing cannula damage and electrode tracks in two animals. $A$, Cannula damage in animal 17A. $B$, Electrode track and lesion marking the electrode track (black arrow) in animal $17 \mathrm{~A}, 4 \mathrm{~mm}$ from the tip of the cannula. $C$, Cannula damage in animal 12A. D, Lesion from electrode track (black arrow) in animal 12A, $2 \mathrm{~mm}$ from the tip of the cannula. Scale bars, $200 \mu$. 
ocular dominance which usually results from monocular deprivation. There were some minor procedural differences between the two laboratories. Our kittens were kept in the dark and exposed to the light for a comparatively short period of time, because they were usually littermates of other kittens which were being exposed to a rotating drum with vertical stripes during the same period of time. In all cases we infused 6-OHDA directly into the cortex with a minipump; the initial experiments of Kasamatsu and Pettigrew $(1976,1979)$ were done with intraventricular injections of 6-OHDA, and minipumps were used in their later experiments, including those on the recovery from the effects of monocular deprivation (Kasamatsu et al., 1979, 1981b). Kasamatsu and Pettigrew generally sutured the eyelids shut in their kittens on the same day that they implanted the cannula in the cortex. In contrast, we allowed a few days for the 6-OHDA to take effect before doing the cyc suture. It is also worth noting that the experiments were difficult, and that almost half the kittens that we started to rear could not be included in the results for technical reasons (the pump came loose, the kitten died, etc.). Nevertheless, the general conclusions on monocular deprivation from the two laboratories are the same.

A point on which our results differ from those of Kasamatsu and Pettigrew is that we found that a substantial number of cells dominated by the closed eye in the 6-OHDA animals had nonspecific receptive field properties. This can probably be attributed to differences in the rearing procedures. Because our animals were in the dark before the eye closure, the cortex in our animals never received a textured and contoured input through the sutured eye at any time in the animal's life. Kasamatsu and Pettigrew's animals did, before the eye suture. At the same time, this asymmetry in the receptive field properties from the two eyes shows that 6-OHDA did not make the cortex totally neutral to the effects of visual input. Indeed, the ocular dominance histogram, although flatter than the monocularly deprived conlrols, showed more monocular cells than normal animals usually do, so the ocular dominance shifts were not totally prevented in our animals either.

Our results with directional deprivation support the notion that 6-OHDA reduces effects that are specific to a particular deprivation. Rearing in a continually moving environment changes the properties of directionally selective cells without affecting other properties; suture of one eye changes ocular dominance without affecting other properties; what 6-OHDA does is reduce the directional changes in the first case and reduce the ocular dominance changes in the second case, again without affecting other properties. There is no evidence in our data that 6-OHDA produces a general disruption of cortical activity. The percentage of omnidirectional cells was high in all animals, but not significantly higher in the 6-OHDA animals than the controls. Directionally deprived animals were kept in the dark until the minipump was implanted, and also after that except when sitting in the drum, so that they would not be exposed to contours moving in the wrong direction. Monocularly deprived animals were usually littermates of these, so they were treated similarly. It is well known that rearing kittens in the dark, or with both eyes sutured, leads to an increase in the percentage of cells with nonspecific receptive field properties (Wiesel and Hubel, 1965; Pettigrew, 1974; Fregnac and Imbert, 1978; Mower et al., 1981; see also Movshon and van Sluyters, 1981; Sherman and Spear, 1982). This almost certainly accounts for the high percentage of omnidirectional cells.

One hypothesis which has been put forward for the action of 6-OHDA on monocularly deprived animals is that it leads to a general decrease of inhibition. A decrease of inhibition leads to an increase in the number of cells that can be driven by the deprived eye (Duffy et al., 1976; Kratz et al., 1976; Sillito et al., 1981) and also an increase in the number of cells that can be driven binocularly in normal animals (Sillito et al., 1981). It is difficult to explain our results on directionally deprived animals by this hypothesis. Any such general mechanism would be expected to act on all unidirectional cells, and there is no reason to suppose that it might differentiate cells preferring rightward movement from those preferring leftward movement.

The mechanism of action of 6-OHDA is that it is taken up preferentially by catecholamine terminals, where formation of free radicals, quinones, or other substances has toxic effects (for review, see Jonsson, 1980). There may also be damage to other cells, presumably from the formation of these same substances. The damage to other cells is of particular concern when the 6-OHDA is administered into the ventricles or directly into the cortex. Our histology did not show general damage to the cortex in the area of the electrode penetrations, just as the physiology did not show a reduction in specificity of the receptive fields of the cells recorded there. We cannot exclude the possibility that examination of the tissue by electron microscopy or use of some other staining technique might show damage or the possibility that 6-OHDA led to a general transient disruption of cortical activity, which was gone by the time that we made our recordings. We can say that the physiological and anatomical methods usually used for studying visually deprived animals did not show up any general damage.

Kasamatsu and Pettigrew have suggested that 6OHDA in these experiments is acting specifically on the noradrenaline (NA) system. This is an appealing hypothesis, because the NA system, which arises from the locus coeruleus, is a diffuse system (for reviews see Moore and Bloom, 1974; Amaral and Sinnamon, 1980). It has also been implicated in some learning and attention processes (see Amaral and Sinnamon, 1980; McNaughton and Mason, 1980). Our experiments do not provide evidence on the specificity of the results to the NA system. The best evidence is that, if NA is infused into a cortex previously depleted of 6-OHDA, ocular dominance shifts do occur after eye suture (Pettigrew and Kasamatsu, 1978; Kasamatsu, et al., 1979, 1981b). Some doubt has been thrown on the hypothesis, because 6-OHDA administered at birth does not prevent ocular dominance shifts, even though NA in the cortex is substantially reduced (Bear and Daniels, 1983). Although the NA concentration in cerebral cortex increases after birth in both cats and rhesus monkey (Himwich et al., 1967; Goldman-Rakic and Brown, 1982), and the time course might bear some relationship to the critical period in striate cortex if it were measured specifically in that tissue, there are no 
anatomical, physiological, or biochemical changes in the NA system known to coincide with the end of the critical period. Therefore, one has to say that the mechanism of action of 6-OHDA in these experiments is not conclusively proved. At the same time, our experiments show that it acts on more than one type of visual deprivation, probably involving more than one type of synapse, and that the effects are specific to the particular type of deprivation used.

\section{References}

Amaral, D. G., and H. M. Sinnamon (1980) The locus coeruleus: Neurobiology of a central noradrenergic nucleus. Prog. Neurobiol. 9: 147-196.

Bear, M. F., and J. D. Daniels (1983) The plastic response to monocular deprivation persists in kitten visual cortex after chronic depletion of norepinephrine. J. Neurosci. 3: 407-416.

Berman, N., and N. W. Daw (1977) Comparison of the critical periods for monocular and directional deprivations in kittens. J. Physiol. (Lond.) 265: 249-254.

Bloom, F. E., S. Algeri, A. Gropetti, A. Revuelta, and E. Costa (1969) Lesions of central norepinephrine terminals with 6$\mathrm{OH}$-dopamine: Biochemistry and fine structure. Science 166: 1284-1286.

Cynader, M., N. Berman, and A. Hein (1975) Cats raised in a one-directional world: Effects on receptive fields in visual cortex and superior colliculus. Exp. Brain Res. 22: 267-280.

Daw, N. W., and M. Ariel (1980) Properties of monocular and directional deprivation. J. Neurophysiol. 44: 280-294.

Daw, N. W., and H. J. Wyatt (1976) Kittens reared in a unidirectional environment: Evidence for a critical period. J. Physiol. (Lond.) 257: 155-170.

Daw, N. W., N. Berman, and M. Ariel (1978) Interaction of critical periods in the kitten visual cortex. Science 199: 565567.

Duffy, F. H., S. R. Snodgrass, J. C. Burchfiel, and J. L. Conway (1976) Bicuculline reversal of deprivation amblyopia in the cat. Nature 260: 256-257.

Fregnac, Y., and M. Imbert (1978) Early development of visual cortical cells in normal and dark-reared kittens: Relationship between orientation selectivity and ocular dominance. J. Physiol. (Lond.) 278: 27-44.

Goldman-Rakic, P. S., and R. M. Brown (1982) Postnatal development of monoamine content and synthesis in the cerebral cortex of rhesus monkeys. Dev. Brain Res. 4: 339349.

Himwich, H. E., G. E. Pscheidt, and A. K. Schweigerdt (1967) Comparative studies on development of biogenic amines in brains of growing rabbits and cats. In Regional Development of the Brain in Early Life, A. Minkowski, ed., pp. 273-296, Davis, Philadelphia.

Hubel, D. H., and T. N. Wiesel (1959) Receptive fields of single neurons in the cat's striate cortex. J. Physiol. (Lond.) 148: 574-591.

Hubel, D. H., and T. N. Wiesel (1970) The period of susceptibility to the physiological effects of unilateral eye closure in kittens. J. Physiol. (Lond.) 206: 419-436.

Itakura, T., T. Kasamatsu, and J. D. Pettigrew (1981) Norepinephrine containing terminals in kitten visual cortex: Laminar distribution and ultrastructure. Neuroscience 6: 159-175.

Jonsson, G. (1980) Chemical neurotoxins as denervation tools in neurobiology. Annu. Rev. Neurosci. 3: 169-187.

Kasamatsu, T., and J. D. Pettigrew (1976) Depletion of brain catecholamines: Failure of ocular dominance shift after monocular occlusion in kittens. Science 194: 206-208.
Kasamatsu, T., and J. D. Pettigrew (1979) Preservation of binocularity after monocular deprivation in the striate cortex of kittens treated with 6-OHDA. J. Comp. Neurol. 185: 139162.

Kasamatsu, T., J. D. Pettigrew, and M. Ary (1979) Restoration of visual cortical plasticity by local microperfusion of norepinephrine. J. Comp. Neurol. 185: 163-182.

Kasamatsu, T., T. Itakura, and G. Jonsson (1981a) Intracortical spread of exogenous catecholamines: Effective concentration for modifying cortical plasticity. J. Pharmacol. Exp. Ther. 217: 841-850.

Kasamatsu, T., J. D. Pettigrew, and M. Ary (1981b) Cortical recovery from effects of monocular deprivation: Acceleration with norepinephrine and suppression with 6-hydroxydopamine. J. Neurophysiol. 45: 254-266.

Kelly, J. P., and D. C. van Essen (1974) Cell structure and function in the visual cortex of the cat. J. Physiol. (Lond.) 238: 515-547.

Kratz, K. E., P. D. Spear, and D. C. Smith (1976) Postcritical period reversal of effects of monocular deprivation on striate cortex cells in the cat. J. Neurophysiol. 39: 501-511.

McNaughton, M., and S. T. Mason (1980) The neuropsychology and neuropharmacology of the dorsal ascending noradrenergic bundle-a review. Prog. Neurobiol. 14: 157-219.

Moore, R. Y., and F. E. Bloom (1979) Central catecholamine neuron systems: Anatomy and physiology of the norepinephrine and epinephrine systems. Annu. Rev. Neurosci. 2: 113168.

Movshon, J. A., and R. C. Van Sluyters (1981) Visual neural development. Annu. Rev. Psychol. 32: 477-522.

Mower, G. D., D. Berry, J. L. Burchfiel, and F. H. Duffy (1981) Comparison of the effects of dark rearing and binocular suture on development and plasticity of cat visual cortex. Brain Res. 220: 255-267.

Pettigrew, J. D. (1974) The effect of visual experience on the development of stimulus specificity by kitten central neurones. J. Physiol. (Lond.) 237: 49-74.

Pettigrew, J. D., and T. Kasamatsu (1978) Local perfusion of noradrenaline maintains visual cortical plasticity. Nature 271: 761-763.

Sherman, S. M., and P. D. Spear (1982) Organization of the visual pathways in normal and visually deprived cats. Physiol. Rev. 62: 738-855.

Sillito, A. M. (1977) Inhibitory processes underlying the directional specificity of simple, complex and hypercomplex cells in the cat's visual cortex. J. Physiol. (Lond.) 271: 699-720.

Sillito, A. M., J. A. Kemp, and C. Blakemore (1981) The role of GABAergic inhibition in the cortical effects of monocular deprivation. Nature 291: 318-320.

Tretter, F., M. Cynader, and W. Singer (1975) Modification of direction selectivity of neurons in the visual cortex of kittens. Brain Res. 84: 143-149.

Ungerstedt, U. (1971) Histochemical studies on the effects of intracerebral and intraventricular injection of 6-hydroxydopamine on monoamine neurons in the rat brain. In 6-Hydroxydopamine and Catecholamine Neurons, T. Malmfors and H. Thoenen, eds., pp. 101-127, North-Holland, Amsterdam.

Uretsky, N. J., and L. L. Iversen (1970) Effects of 6-hydroxydopamine on catecholamine containing neurons in the rat brain. J. Neurochem. 17: 269-278.

Wiesel, T. N., and D. H. Hubel (1963) Single cell responses in striate cortex of kittens deprived of vision in one eye. $\mathrm{J}$. Neurophysiol. 26: 1503-1517.

Wiesel, T. N., and D. H. Hubel (1965) Comparison of the effects of unilateral and bilateral eye closure on cortical unit responses in kittens. J. Neurophysiol. 28: 1029-1040. 